\title{
Correction: Oral leukoplakia, a clinical-histopathological study in 412
} patients

Correspondence:

Departamento de Medicina Oral

Clínica Odontológica

c/ Gascó Oliag, 1

46010 Valencia, Spain

andrea_rubert_ara@hotmail.com

Received: $25 / 10 / 2021$

Accepted: 25/10/202

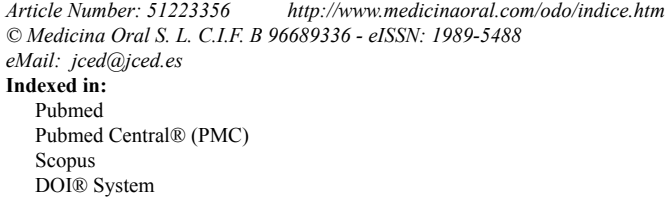

The article by Rubert and colleagues (J Clin Exp Dent 2021;13:e426, 1 May), is not a retraction, this is a correction of the article. 